\title{
Electrolyte Composition for Distinguishing Corrosion Mechanisms in Steel Alloy Screening
}

\author{
Ingmar Bösing, Jorg Thöming, and Michael Baune \\ Center for Environmental Research and Sustainable Technology (UFT), University of Bremen, Leobener Straße 6, Bremen, Germany \\ Correspondence should be addressed to Ingmar Bösing; ingmar.boesing@uni-bremen.de
}

Received 17 August 2017; Accepted 27 November 2017; Published 24 December 2017

Academic Editor: Francisco Javier Perez Trujillo

Copyright (C) 2017 Ingmar Bösing et al. This is an open access article distributed under the Creative Commons Attribution License, which permits unrestricted use, distribution, and reproduction in any medium, provided the original work is properly cited.

\begin{abstract}
The formation and breakdown of passive layers due to pitting corrosion are a major cause of failure of metal structures. The investigation of passivation and pitting corrosion requires two different electrochemical measurements and is therefore a time consuming process. To reduce time in material characterization and to study the interactions of both mechanisms, here, a combined experiment addressing both phenomena is introduced. In the presented electrolyte the different corrosion mechanisms are distinguished and investigated by cyclic voltammograms and polarization scans. The measurements show a passive area, metastable pit growth, and pitting corrosion as well as repassivation. The pitting corrosion is separated from additional dissolution processes and the standard deviation of the corrosion potential is smaller than in other electrolytes. Both passivation and pitting corrosion can be observed in one measurement without additional corrosion attacks. The deviation between different measurements of the same steel is small; this is helpful for the screening of similar materials.
\end{abstract}

\section{Introduction}

The broad range of existing corrosion phenomena can be investigated through numerous electrochemical methods. A great deal of different set-ups is known to study various material and corrosion parameters [1], but the complex nature and the interactions between experimental factors, such as electrolyte composition or temperature and the different corrosion phenomena, like passivation, pitting corrosion or inhibitions, impede studying the single mechanisms separately.

Exploring large sets of samples requires high throughput methods that allow scanning a wide range of mechanical, physical, or chemical parameters. In corrosion science, high throughput methods are used to investigate wide fields of corrosion on different materials [2], coatings [3], corrosion phenomena such as corrosion inhibitors [4], pretreatments [5], and corrosion mechanism [6] like pitting corrosion [7]. Typically, each corrosion phenomenon measurement requires its own set-up. Polarization scans in aggressive media (containing halides), for instance, are performed to investigate pitting corrosion. In contrast to this, to study passivation processes, cyclic voltammograms are recorded in passivation promoting electrolytes.
Pitting corrosion is a localized attack on different materials like iron, chromium, nickel, cobalt, and stainless steel that results in deep pits in the material. These pits can lead to component failure or act as an initiation for cracking [8]. Particularly the passivated and technically essential austenitic steels can be affected by pitting corrosion. In an environment that favors pitting corrosion, halide ions or other components are present that lead to a breakdown of passivity on impurities and imperfections of the passive layers [9]. In the present manuscript we focus on chloride ions that are present in media such as seawater and pharmaceutical solutions, to force a breakdown of passivity.

The passivity of iron-based materials is caused by a formation of an oxide layer on the surface of the metal. A higher chromium content in the alloy leads to a more protective passive film through the formation of an interlinked chromium oxide network $[10,11]$. The passive film is formed either by a spontaneous reaction or by (electrochemical) surface treatments, such as cyclic potentiodynamic polarization [12]. The protectiveness and thermodynamic stability of the passive layer depend on different aspects like temperature and $\mathrm{pH}$-value $[11,13]$. The passivation of iron is faster and better in environments with a high $\mathrm{pH}$-value. In alkaline 
solutions $(\mathrm{pH}>11.5)$, the passivation of iron usually happens spontaneously [14]. The passive layer is commonly not thicker than a few nanometers and protects the metal surface against reactions with the environment. While the formation of passive layers is a crucial mechanism that prevents many construction materials from general corrosion, it makes the same alloys susceptible against pitting corrosion [8].

The passive film formed on stainless steel consists of two parts, an inner chromium oxide layer and an outer ironoxide layer $[15,16]$. If the chromium content is high enough, an interlinked chromium oxide network forms within the passive films and makes it insoluble $[14,17,18]$.

The breakdown of passivity can result from different mechanisms, from which the following three are mainly discussed in the literature [19]: in the penetration mechanism the aggressive ions (halide) penetrate through the passive layer at imperfections and react with the metal [20, 21]. According to the film breakdown mechanism, there are breaks within the film that give the halide anions direct access to the metal surface $[22,23]$. The adsorption of aggressive anions on the oxide surface can lead to surface tension that results in additional breaks in the passive layer and allows anions to get in contact with the bare metal $[24,25]$. The third mechanism assumes that the adsorption of the halides results in the transfer of metal cations from the oxide to the electrolyte. In this manner, the passive layer becomes thinner and is finally completely removed at certain points $[26,27]$.

After pit initiation/breakdown of passivity pit growth occurs. Two types of pits are distinguished. At the beginning of pitting, metastable pits occur; these pits can be repassivated. Under certain circumstances (e.g., critical age [28], pit characteristics [29], and high external potentials) and when the potential difference between the active and passive region is high enough, stable pit growth starts.

To study different corrosion phenomena and mechanisms, sample preparation, sample design, choice of the electrolyte, and experimental setting play an important role [30]. So far, the investigation of passivation requires different electrolytes than the investigation of crevice corrosion or pitting corrosion.

A large amount of techniques exists to form and analyze the passive layers on stainless steel. As an electrochemical technique, cyclic voltammetry in different electrolytes (e.g., sulphuric acid [31], borate buffer [11], sodium chloride [32], or phosphate buffer [12]) is commonly used. The formation of a passive layer on iron requires an aqueous environment that favors the formation of an insoluble iron-oxide complex (e.g., by a high $\mathrm{pH}$-value). In addition to electrolytes that show a clear passivation behavior, one can also use electrolytes that represent the application areas of the tested materials, for example, phosphate-buffered saline for medical use or concrete [33]. The peak current at the active-passive region, the passive current, and the beginning of the transpassive region are some values that are used to interpret the formation and stability of the passive layers. For information about the pitting corrosion resistance, potentiodynamic polarization curves in sodium chloride solution are usually performed. The corrosion potential $E_{\text {corr }}$, the pitting potential $E_{\text {pit }}$, noticeable by a rapid increase of the current density, and the repassivation potential $E_{r}$ describe the corrosion behavior in aggressive media [25].

Especially when the investigated materials only show slight differences, the statistical nature of corrosion phenomena makes clear statements about the studied materials difficult. In this paper, an electrolyte composition is described consisting of phosphate buffer and sodium chloride which makes it possible to investigate both passivation and pitting corrosion of steel alloys in one single measurement. In order to illustrate that differences between the analyzed alloys become much clearer in the proposed electrolyte compared to commonly applied electrolytes, we first investigated the mechanism separately: we performed cyclic voltammograms in pure phosphate buffer to depict the passivation and polarization scans in sodium chloride solution to describe the pitting corrosion processes. In a next step we compared this with CVs and polarization scans in phosphate buffer containing a specific amount of sodium chloride and underlined our findings with microscope recordings. This allows us to demonstrate the advantage of the proposed electrolyte using two stainless steels (AISI 304 and AISI 420) and a bearing steel with a very low chromium content (AISI 5210).

\section{Experimental}

The cyclic voltammetry measurements were done in $0.1 \mathrm{M}$ phosphate buffer $(\mathrm{pH}=7.5)$ and phosphate buffer containing different amounts of $\mathrm{NaCl}$. The polarization scans were recorded in $3.5 \mathrm{wt} . \% \mathrm{NaCl}$ solution and phosphate buffer containing $3.5 \mathrm{wt} . \% \mathrm{NaCl}$. All measurements were carried out at room temperature. A three-electrode cell was used for the experiments. A platinum electrode was used as counter electrode and a $\mathrm{Ag} / \mathrm{AgCl}$ electrode as reference electrode. All potentials in this paper are referred to the $\mathrm{Ag} / \mathrm{AgCl}$ electrode.

As working electrodes, we used three different standard alloys, with a 2-dimensional circular surface $(10 \mathrm{~mm}$ diameter), all of them embedded in a Teflon holder. The chemical compositions of the working electrode materials were expected to be in the standard range (Table 1).

Before each measurement, the working electrode was wet polished with $\mathrm{SiC}$ emery paper up to 2000 grit. Afterwards, the electrodes were sonicated in deionized water and degreased in ethanol.

The cyclic voltammetry measurements were carried out with a scan velocity of $100 \mathrm{mVs}^{-1}$ from $-800 \mathrm{mV}$ to $1100 \mathrm{mV}$ for different numbers of cycles. The potentiodynamic polarization scans were carried out with a scan velocity of $1 \mathrm{mVs}^{-1}$ and started at $-700 \mathrm{mV}$ while ending at $700 \mathrm{mV}$. For all experiments, the PGU 2A-OEM potentiostat (IPS) was used.

\section{Results and Discussion}

3.1. Cyclic Voltammetry in Phosphate Buffer. To understand the passivation behavior of the different alloys, we carried out cyclic voltammograms in 0.1 molar phosphate buffer. From the anodic and cathodic peaks as well as from the differences between the cycles and the different alloys, conclusions about the passivation process can be drawn. The peak location is related to the reacting species and the peak height to the 
TABLE 1: Standard range of chemical composition of the working electrodes (wt.\%) [34].

\begin{tabular}{|c|c|c|c|c|c|c|c|c|}
\hline Alloy & $\mathrm{C}$ & $\mathrm{Si}$ & $\mathrm{Mn}$ & $\mathrm{P}$ & $S$ & $\mathrm{Cr}$ & $\mathrm{Ni}$ & $\mathrm{N}$ \\
\hline AISI 5210 & $0.93-1.05$ & $0.15-0.35$ & $0.25-0.45$ & $\leq 0.025$ & $\leq 0.015$ & $1.35-1.6$ & & \\
\hline AISI 420 & $0.43-0.5$ & $\leq 1.0$ & $\leq 1.0$ & $\leq 0.4$ & $\leq 0.03$ & $12.5-14.5$ & & \\
\hline AISI 304 & $\leq 0.7$ & $\leq 1.0$ & $\leq 2.0$ & $\leq 0.045$ & $\leq 0.03$ & $17.5-19.5$ & $8.0-10.5$ & $\leq 0.1$ \\
\hline
\end{tabular}
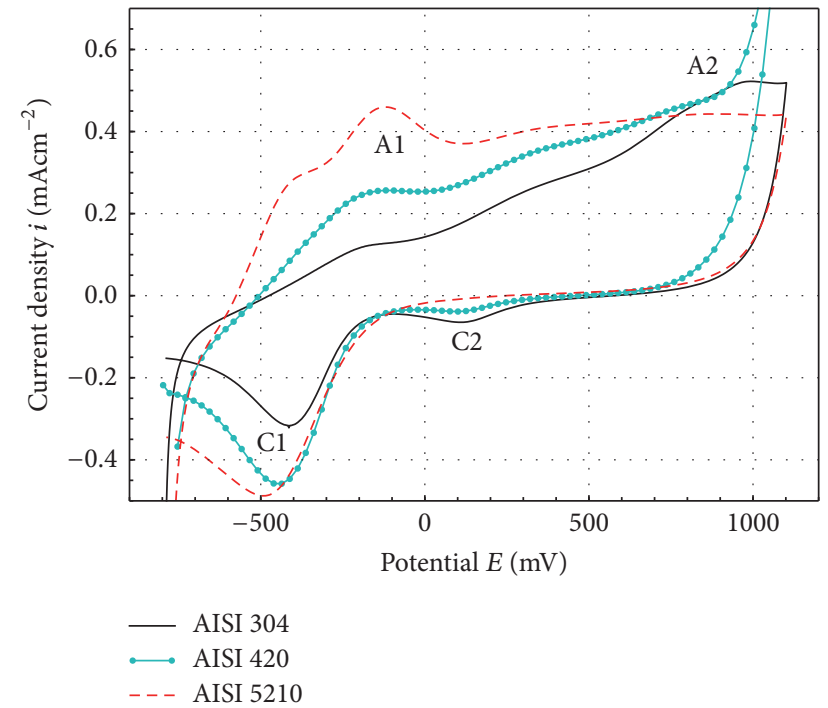

FIGURE 1: 1st cycle of cyclic voltammograms for AISI 5210, AISI 420, and AISI 304 recorded in phosphate buffer. The scans are recorded from $-800 \mathrm{mV}$ to $1100 \mathrm{mV}$ with a scan velocity of $100 \mathrm{mVs}^{-1}$. All potentials are measured against the $\mathrm{Ag} / \mathrm{AgCl}$ electrode.

converted charge and mass, and the passive current density allows conclusions about the protectiveness of the passive layers.

Figure 1 shows the first cycle of the cyclic voltammograms of the three alloys. The CVs display oxidation peaks for the iron and chromium species during anodic polarization and reduction peaks of these species during cathodic polarization. The peak heights are related to the chromium contents and thus also to the protectiveness of the passive layers.

The anodic polarization scan shows different oxidation peaks and shoulders and no passive area. Two peaks (A1 and A2) are of particular interest. The peaks $\mathrm{A} 1$ are associated with the oxidation of $\mathrm{Fe}(\mathrm{II})$ species to $\mathrm{a}_{3} \mathrm{O}_{4} / \mathrm{FeO}$ hydrated layer that forms on a preexisting $\mathrm{Cr}$ (III) oxide network. The peaks A2 belong to the oxidation of $\mathrm{Cr}$ (III) to $\mathrm{Cr}(\mathrm{VI})$-species. When the polarization direction changes, a small peak can be seen for the reduction of the $\mathrm{Cr}$ (IV)-species to $\mathrm{Cr}$ (III) oxide (C2) and at more negative potentials a peak $(\mathrm{Cl})$ is associated with the reduction of the $\mathrm{Fe}_{3} \mathrm{O}_{4} / \mathrm{FeO}$ layer to $\mathrm{Fe}(\mathrm{III})[11,12,35,36]$.

With increasing chromium content in the different alloys the oxidation peaks A1 decrease, while the oxidation peaks A2 increase. The area under the peaks is related to the transferred charge during the oxidation processes. The larger the area is the more the charge is transferred during the oxidation of the specific species. The same applies to the reduction peaks.

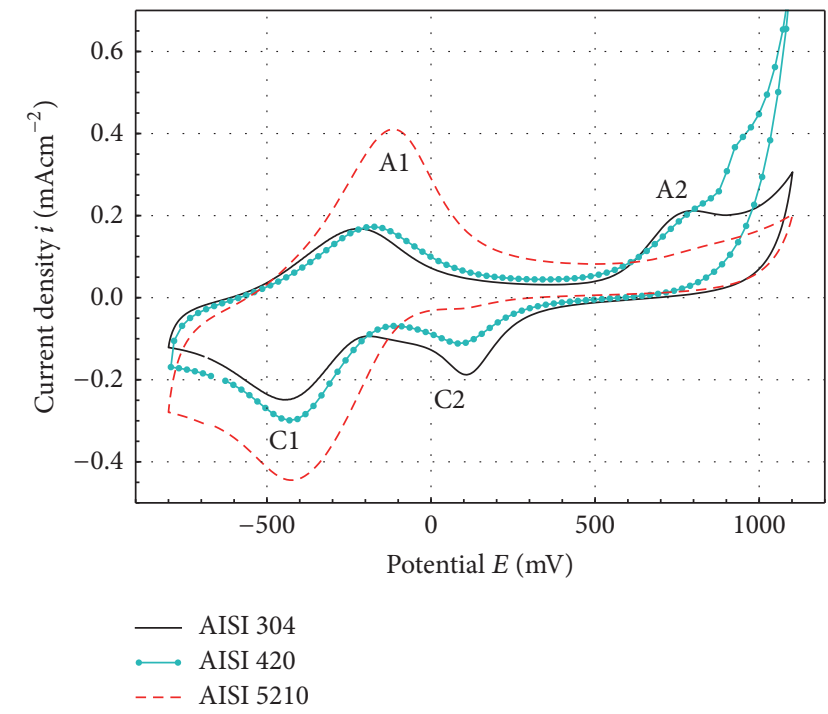

FIGURE 2: 10th cycle of cyclic voltammograms for AISI 5210, AISI 420, and AISI 304 recorded in phosphate buffer. The scans are recorded from $-800 \mathrm{mV}$ to $1100 \mathrm{mV}$ with a scan velocity of $100 \mathrm{mVs}^{-1}$. For each electrode the 10th cycle is displayed. All potentials are measured against the $\mathrm{Ag} / \mathrm{AgCl}$ electrode.

There is nearly no passive region, but the current between peak A1 and peak A2 increases with decreasing chromium content. AISI 420 already shows rapid increase in current density which is related to dissolution and oxygen evolution beginning at $900 \mathrm{mV}$. The absence of a clear passive region reveals the lack of the protective passive layer formed in the first cycle.

At higher cycles, the oxidation/reduction peaks are better visible and the growth of the passive layer leads to a passive region. The height of the active/passive region and of the passive current density is connected to the ability to passivate (Figure 2).

Again, with increasing chromium content peak A1 decreases while peak A2 increases. The current density in the passive region is the lowest for AISI 304 (highest chromium content) and increases with decreasing chromium content, but the differences are small.

In the first cycle, the peaks are not clear and there is nearly no passive region. This indicates the absence of protection through the $\mathrm{Fe}_{3} \mathrm{O}_{4} / \mathrm{FeO}$ hydrated layer formed in the first cycle. At the first cycle the $\mathrm{Cr}(\mathrm{IV})$-species is not interlinked in the Fe-oxide layer and soluble. The high oxidation peak A2 and the very small reduction $\mathrm{Cr}(\mathrm{IV})$ reduction peak underline this. After the first cycles, the Cr(IV)-oxide gets "arrested" [12] (and insoluble) in the Feoxide and the protective passive layer is formed [14]. 
The small active/passive region, presented in Figure 2, of AISI 304 and AISI 420 depicts a faster passivation than the much wider active-passive region of AISI 5210. However, the smaller anodic charge below A1 also means less reaction to form the passive layer. On the other hand, the larger $\mathrm{Cr}$ (III)oxidation peak A2 indicates higher chromium content while the passivation improves. Interestingly, AISI 420 shows a transpassive region dedicated to the evolution of oxygen and the dissolution of iron which neither AISI 304 nor AISI 5210 show. An explanation of this behavior requires further information.

The cyclic voltammograms point out the general ability of the different alloys to passivate and form a protective passive layer on the surface of the materials. All alloys show passivation peaks and a passive region, but the differences between the passive current of AISI 304 and AISI 420 are very small.

3.2. Potentiodynamic Polarization Scans in NaCl Solution. As stated above, in order to gather more information on the corrosion resistance, the stability and protectiveness of the passive layer, and pitting behavior additional experiments are necessary.

Polarization scans in sodium chloride solution were recorded to determine the characteristic corrosion potential $E_{\text {corr }}$ and the pitting potential $E_{\text {pit }}$ as well as the region of metastable pit growth. In combination with the CVs we were able to get more information about the interaction between passivation and pitting.

Figure 3 shows the potentiodynamic polarization scans of AISI 304, AISI 420 and AISI 5210 in 3.5 wt.\% NaCl solution. The corrosion potential $E_{\text {corr }}$ increases with increasing chromium content. After passing the corrosion potential, AISI 5210 shows direct dissolution, noticeable by the rapid increase of current density. There is neither a passive region nor a region of metastable pit growth as for stainless steels. In contrast, AISI 304 and AISI 420 show metastable pit growth overlapped by an increase in current density related to constant metal dissolution. The region of metastable pit growth lies between the corrosion potential (AISI 304: $-275.19 \mathrm{mV}$ ) and the beginning of stable pit growth (AISI 304: $37.95 \mathrm{mV}$ ). The characteristic potentials of the potentiodynamic polarization scans in $\mathrm{NaCl}$ are listed in Table 2.

The polarization scans in sodium chloride disclose clear disadvantages: there is not a passive area to draw conclusions about passivation, nor is the pit growth separated by additional dissolution processes. Further, both stainless steels show similar corrosion potentials, although their corrosion resistance is quite different.

3.3. Cyclic Voltammetry in Phosphate Buffer with $\mathrm{NaCl}$. To overcome the mentioned limitations and in order to provide a better understanding of passivation processes, the breakdown of passivity, and corrosion characteristics, we suggest an electrolyte composition of phosphate buffer and sodium chloride. While polarizing in phosphate buffer, a more protective passive layer can form on stainless steel. By adding sodium chloride, the $\mathrm{Cl}^{-}$-ions in the electrolyte can force dissolution, breakdown of the passive film, and pitting corrosion.
TABLE 2: Characteristic values of polarization scans in $3.5 \mathrm{wt} . \% \mathrm{NaCl}$ solution.

\begin{tabular}{lccc}
\hline Alloy & $E_{\text {corr }}$ & $E_{\text {pit }}$ & Metastable pit growth \\
\hline AISI 304 & $-275.19 \mathrm{mV}$ & $37.95 \mathrm{mV}$ & $-275.19 \mathrm{mV}-37.95 \mathrm{mV}$ \\
AISI 420 & $-319.6 \mathrm{mV}$ & $-126.18 \mathrm{mV}$ & $-258.22 \mathrm{mV}--80.99 \mathrm{mV}$ \\
AISI 5210 & $-405.59 \mathrm{mV}$ & & \\
\hline
\end{tabular}

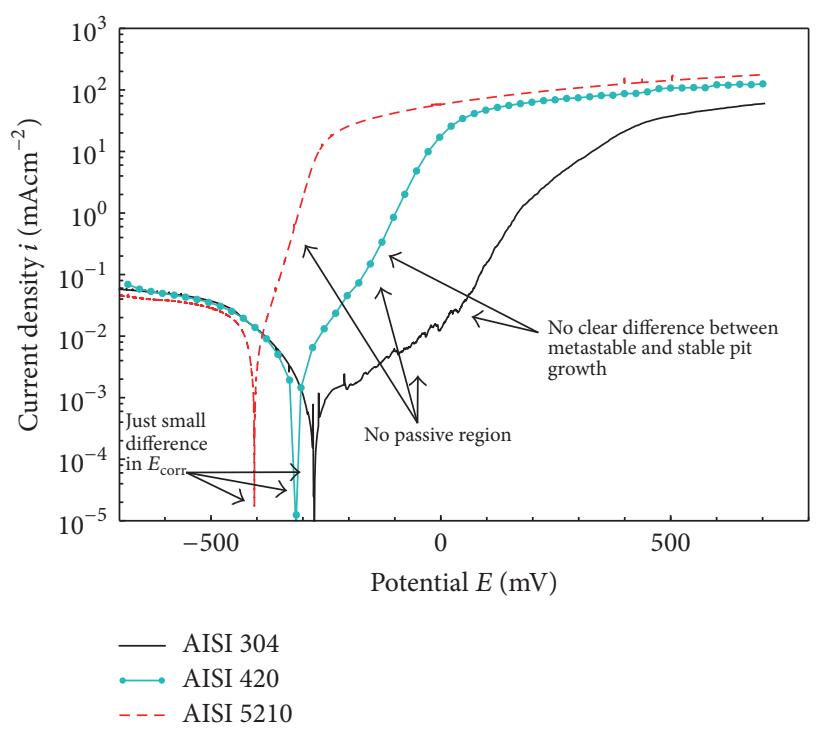

FIgUre 3: Potentiodynamic polarization scan in $3.5 \mathrm{wt} . \% \mathrm{NaCl}$ solution. The measurements are performed from $-700 \mathrm{mV}$ to $700 \mathrm{mV}$ with a scan velocity of $1 \mathrm{mVs}^{-1}$. All potentials are recorded against the $\mathrm{Ag} / \mathrm{AgCl}$ electrode.

By adding different amounts of sodium chloride, stable pit growth and passivation processes are visible. With increasing amounts of sodium chloride, the dissolution due to pitting corrosion shifts to more negative potentials and the cathodic polarization curves change their appearance.

Additionally small amount of sodium chloride (0.2 wt.\% and $0.3 \mathrm{wt} . \%)$ results in a slightly higher current density during the anodic polarization in the first cycles. The cathodic polarization curve also shows different behavior. By adding sodium chloride, anodic current is measurable during the beginning of the cathodic polarization. With an increasing amount of sodium chloride, the anodic current grows to a hysteresis (Figure 4). The increase of anodic current matches the occurrence of stable pits during the anodic scan at high potentials. These pits can still grow during the cathodic polarization in regions of metastable pit growth [35, 37].

At low sodium chloride concentrations, the anodic peaks are still visible for the oxidation of $\mathrm{Fe}$-species to $\mathrm{Fe}_{3} \mathrm{O}_{4} / \mathrm{FeO}$ layers and $\mathrm{Cr}$ (III) to $\mathrm{Cr}(\mathrm{IV})$-species and the equivalent reduction reactions. At higher $\mathrm{NaCl}$ concentrations (Figure 4: 1 wt. $\% \mathrm{NaCl}$ ), the dissolution processes overlay the other reactions.

For a small amount sodium chloride, the shape of cycle 10 and cycle 20 is similar to the cycles without sodium chloride (compare Figure 5 cycle 10 and cycle 20 with Figure 2). This exemplifies that the alloy can be repassivated and form a 


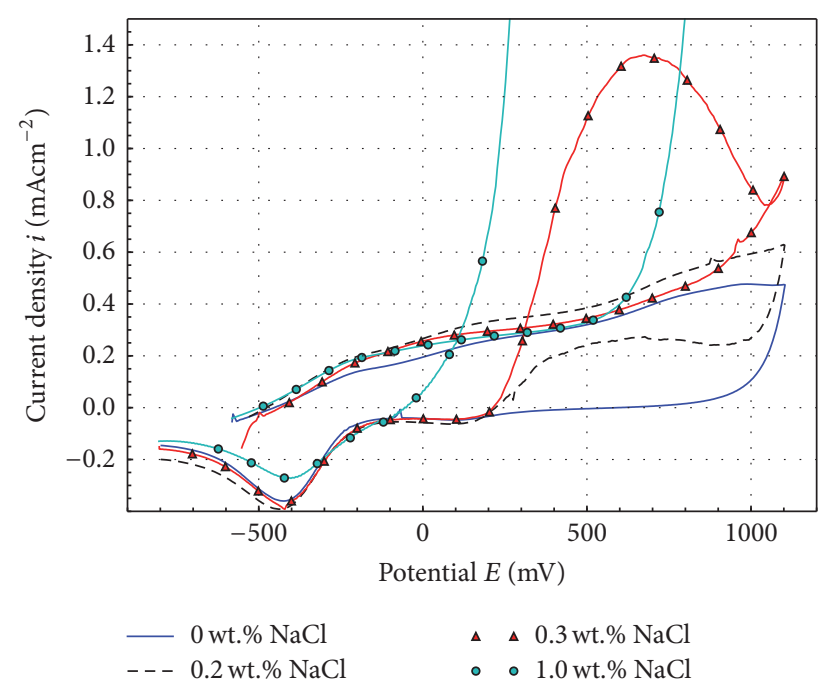

FIGURE 4: First cycle of cyclic voltammograms of AISI 304 in phosphate buffer with different contents of $\mathrm{NaCl}$. The $\mathrm{CV}$ s are recorded from $-800 \mathrm{mV}$ to $1100 \mathrm{mV}$ with a scan velocity of $100 \mathrm{mVs}^{-1}$. All potentials are measured against a $\mathrm{Ag} / \mathrm{AgCl}$ electrode.

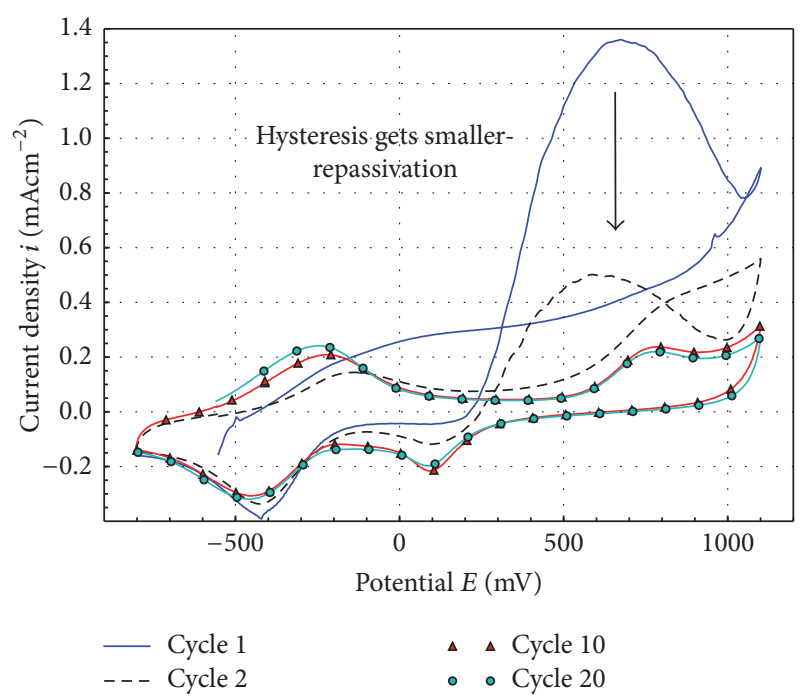

FIGURE 5: Cyclic voltammogram of AISI 304 in phosphate buffer with 0.3 wt. $\% \mathrm{NaCl}$. The scans are recorded from $-800 \mathrm{mV}$ to $1100 \mathrm{mV}$ with a scan velocity of $100 \mathrm{mVs}^{-1}$. All potentials are measured against a $\mathrm{Ag} / \mathrm{AgCl}$ electrode.

protective passive layer against pitting corrosion, even in an aggressive environment.

The combination of phosphate buffer, an electrolyte that enhances passivation processes, and sodium chloride, which leads to pitting corrosion, shows both the passivation of the stainless steel and the growth of the passive layer as well as the breakdown of passivity and the growth of pits on the material surface. The good passivation behavior is also visible through the repassivation of the surface at higher cycles.

At higher amounts of sodium chloride it is more difficult to observe the passivation, because the passive area shrinks and the dissolution overlays characteristics of the

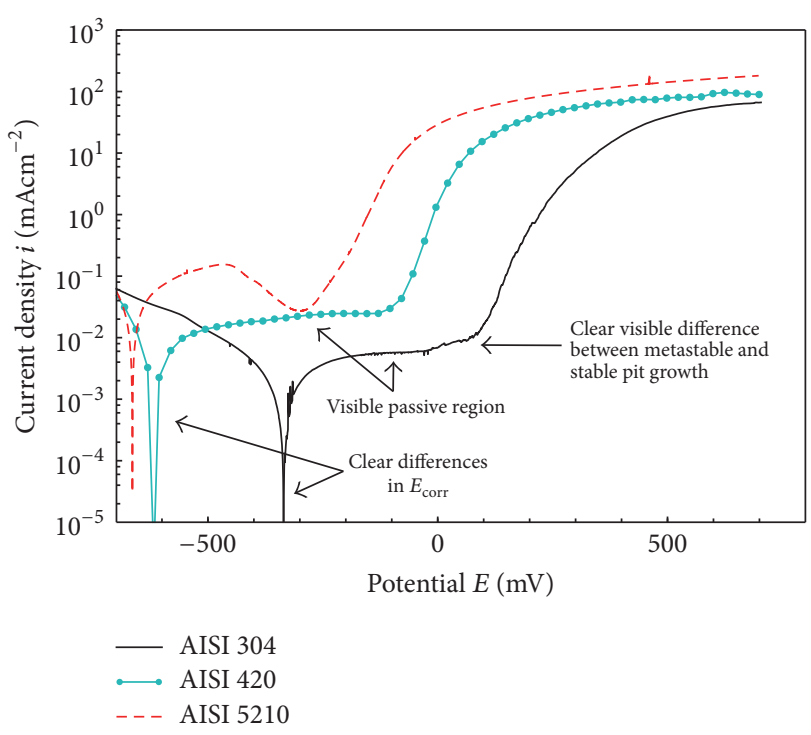

FIGURE 6: Potentiodynamic polarization scans of AISI 304, AISI 420, and AISI 5210 in phosphate buffer with $3.5 \mathrm{wt} . \% \mathrm{NaCl}$.

cyclic voltammograms. For investigations of high amounts of sodium chloride in phosphate buffer on the passivation of different alloys, we used potentiodynamic polarization scans.

3.4. Potentiodynamic Polarization Scans in Phosphate Buffer with $\mathrm{NaCl}$. The advantage of showing both passivation and pitting corrosion is even more distinct for polarization scans in phosphate buffer containing $3.5 \mathrm{wt}$.\% sodium chloride. The CVs already clarify that passivation and pitting corrosion can be separated. During the polarization scans, a clear passive region is visible. This region is followed by metastable pit growths, without further dissolution. At higher potentials the pitting potential $E_{\mathrm{pit}}$ is clearly separated from the other processes (Figure 6).

Similar to measurements in pure sodium chloride solution (Figure 3) the corrosion potential $E_{\text {corr }}$ increases with increasing chromium content. By adding phosphate buffer, the differences between the alloys become more obvious. After passing $E_{\text {corr }}$ all three alloys display different behavior than in pure $\mathrm{NaCl}$ solution. Both stainless steels, AISI 304 and AISI 420, show a clear passive region. The passive current of AISI 304 is significantly lower than the passive current of AISI 420. After the passive region, a region of metastable pit growth is visible, followed by stable pit growth and metal dissolution, noticeable by a rapidly increasing current density.

All characteristic values for the potentiodynamic polarization scan in phosphate buffer with sodium chloride are listed in Table 3. From the measurements it becomes clear that, in contrast to pure $\mathrm{NaCl}$ solution, there is passivation in phosphate buffer with $3.5 \mathrm{wt} . \% \mathrm{NaCl}$. The cyclic voltammograms already show that there are different passivation peaks in phosphate buffer. But even without multiple cycles through all potentials for the formation of the passive layers (multiple formations of $\mathrm{Fe}_{3} \mathrm{O}_{4} / \mathrm{FeOH}$ and an interlinked $\mathrm{Cr}$ (IV)-network with in the layer) a clear passive region is visible. 
TABLE 3: Characteristic values for potentiodynamic polarization scans in phosphate buffer with $3.5 \mathrm{wt} . \% \mathrm{NaCl}$.

\begin{tabular}{lccc}
\hline Alloy & $E_{\text {corr }}$ & $E_{\text {pit }}$ & Metastable pit growth \\
\hline AISI 304 & $-336.3 \mathrm{mV}$ & $78.4 \mathrm{mV}$ & $-12.7 \mathrm{mV}-78.4 \mathrm{mV}$ \\
AISI 420 & $-617.2 \mathrm{mV}$ & $-85.3 \mathrm{mV}$ & $-172.7 \mathrm{mV}--85.3 \mathrm{mV}$ \\
AISI 5210 & $-663.7 \mathrm{mV}$ & & \\
\hline
\end{tabular}

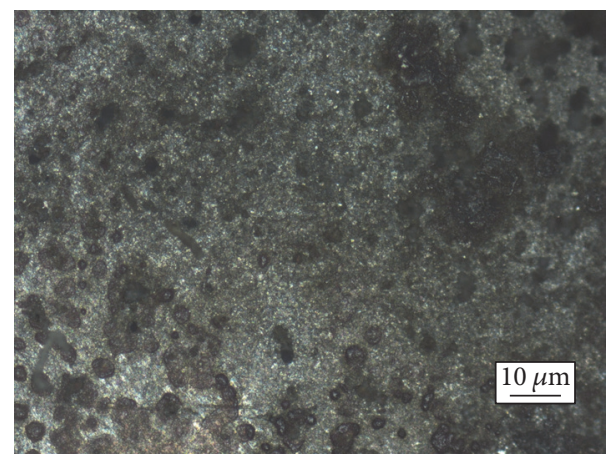

FIGURE 7: Microscope recordings of AISI 420 after polarization scan in 3.5 wt. $\% \mathrm{NaCl}$ solution.

During the anodic polarization of the working electrode the negative phosphate ions $\left(\mathrm{PO}_{4}{ }^{-3}\right)$ adsorb on the electrode surface. Due to the competitive adsorption of the phosphate and chloride ions, less of the aggressive $\mathrm{Cl}^{-}$ions can reach the surface and the pitting potential $E_{\mathrm{pit}}$ moves towards positive potentials [38].

While $E_{\text {pit }}$ is higher in phosphate buffer containing sodium chloride the corrosion potential $E_{\text {corr }}$ is more negative. This illustrates the thermodynamic equilibrium shifts towards the more negative potentials.

At polarization scans in phosphate buffer with additional sodium chloride the region of metastable pit growth is not overlaid by additional dissolution processes. In contrast to that, the region of metastable pit growth, when doing polarization scans in pure sodium chloride, is overlaid by additional dissolution processes. To verify these findings, we took microscope recordings of the surfaces after polarization scans and compared the corrosion attacks.

The polarization scan in pure sodium chloride solution leads to small pits and wide-area attacks (compare Figure 7). This is in good agreement with the observations from Figure 3 where the region of pit growth is overlapped by general metal dissolution. The polarization scans in phosphate buffer with sodium chloride result in big pits surrounded by intact metallic surface and very small pits (Figure 8 ). The microscope recordings underline the potential of the electrolyte combination to separate the pitting corrosion from additional corrosion processes.

3.5. Determination of the Reliability of the Measurements. In order to investigate different materials that differ only slightly from one another, it is essential that the deviations of measurements on the same materials stay small and values of different materials do not overlap. To ensure the workability

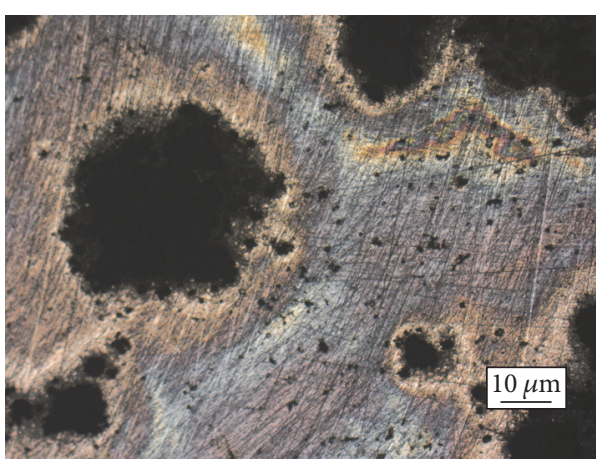

FIGURE 8: Microscope recording of AISI 420 after polarization scan in phosphate buffer containing $3.5 \mathrm{wt} . \%$.

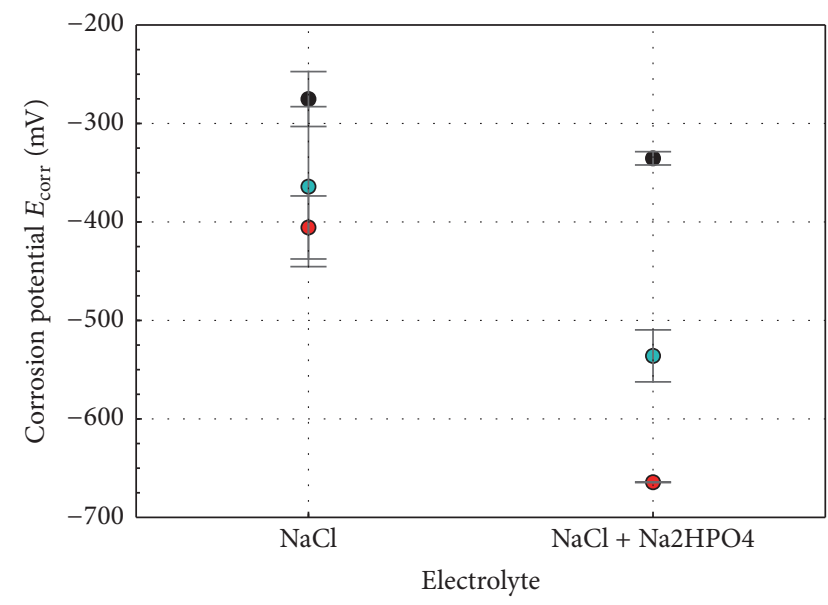

$\begin{array}{lll}\text { - } & \text { AISI } 304 \\ \text { ○ } & \text { AISI } 420 \\ \text { - } & \text { AISI } 5210\end{array}$

FIGURE 9: Corrosion potentials and its standard deviations of AISI 304,420 , and 5210 measured in $\mathrm{NaCl}$ solution and phosphate buffer with NaCl. $\sigma=\sqrt{(1 /(n-1)) \sum\left(x_{i}-\bar{x}\right)^{2}}, n=4$.

of the electrolyte combination, we calculated the standard deviation of the corrosion potentials in pure $\mathrm{NaCl}$ solution as well as in phosphate buffer containing $\mathrm{NaCl}$.

Figure 9 shows the corrosion potentials and its standard deviation of AISI 304, AISI 420, and AISI 5210 for the two different potentiodynamic polarization scans. The corrosion potential for the polarization scans in pure $\mathrm{NaCl}$ solution is higher than in phosphate buffer containing $\mathrm{NaCl}$. The standard deviation for the corrosion potential in phosphate buffer with $\mathrm{NaCl}$ is significantly smaller than in pure $\mathrm{NaCl}$ solution. This allows a better prediction about single corrosion behavior.

\section{Conclusion}

The polarization scans in phosphate buffer with sodium chloride uncover the ability of the material to be passivated and its susceptibility to pitting corrosion. In the case of pitting corrosion, the metastable pit growth is separated from 
additional corrosion phenomena and can be investigated by itself. The microscope recordings underline these findings.

Just small differences between the corrosion potentials in sodium chloride solution are enlarged, and a clear passive region, a region of metastable pit growth, and an exact starting point for stable pit growth are visible. The standard deviation of the characteristic electrochemical values was significantly smaller than in pure $\mathrm{NaCl}$ solution. This is very helpful for the investigation of similar alloys while screening new materials.

The cyclic voltammetry in the electrolyte solution shows both the passivation of the surfaces and the pitting corrosion. The presence of the hysteresis is an additional sign for stable pit growth. After the first cycles, the shape of the scan changed and the last cycles resemble the last cycles in pure phosphate buffer. Hence, repassivation occurs even in the presence of aggressive ions and a surface treatment by cyclic voltammetry in phosphate buffer can enhance the pitting corrosion resistance. By adding a small amount of sodium chloride to the phosphate buffer, the examination of passivation and the breakdown of passivity and the repassivation become possible.

The suggested electrolyte composition is an easily applicable tool for the investigation of passivity and passivation breakdown. The ability to separate metastable pit growth from additional dissolution and the greater separation of the characteristic values in combination with a smaller standard deviation make it a promising electrolyte composition for material research in high throughput steel screening.

\section{Conflicts of Interest}

The authors declare that there are no conflicts of interest regarding the publication of this paper.

\section{Acknowledgments}

Financial support of subproject D03 "Electrochemical High Throughput Characterization of Metallic Micro Samples" of the Collaborative Research Center SFB 1232 "Farbige Zustände" by the German Research Foundation (DFG) is gratefully acknowledged.

\section{References}

[1] P. Marcus and F. Mansfeld, Analytical Methods in Corrosion Science and Engineering, CRC Press, 2006.

[2] M. Balasubramanian, V. Jayabalan, and V. Balasubramanian, "Optimizing pulsed current parameters to minimize corrosion rate in gas tungsten arc welded titanium alloy," The International Journal of Advanced Manufacturing Technology, vol. 39, no. 5-6, pp. 474-481, 2008.

[3] J. He, J. Bahr, B. J. Chisholm et al., "Combinatorial materials research applied to the development of new surface coatings $\mathrm{X}$ : a high-throughput electrochemical impedance spectroscopy method for screening organic coatings for corrosion inhibition," Journal of Combinatorial Chemistry, vol. 10, no. 5, pp. 704-713, 2008.
[4] B. D. Chambers and S. R. Taylor, "Multiple electrode methods to massively parallel test corrosion inhibitors for AA2024-T3," NACE - International Corrosion Conference Series, pp. 0667810667814, 2006.

[5] D. L. Schulz, R. A. Sailer, C. Braun et al., "Trimethylsilanebased pretreatments in a Mg-rich primer corrosion prevention system," Progress in Organic Coatings, vol. 63, no. 2, pp. 149-154, 2008.

[6] N. D. Budiansky, F. Bocher, H. Cong, M. F. Hurley, and J. R. Scully, "Use of coupled multi-electrode arrays to advance the understanding of selected corrosion phenomena," Corrosion, vol. 63, no. 6, pp. 537-554, 2007.

[7] I. Annergren, D. Thierry, and F. Zou, "Localized electrochemical impedance spectroscopy for studying pitting corrosion on stainless steels," Journal of The Electrochemical Society, vol. 144, no. 4, pp. 1208-1215, 1997.

[8] G. S. Frankel, "Pitting corrosion of metals: a review of the critical factors," Journal of The Electrochemical Society, vol. 145, no. 6, pp. 2186-2198, 1998.

[9] K.-H. Tostmann, "Lochkorrosion," in Korrosion, pp. 80-82, WILEY-VCH, Weinheim, Germany, 2001.

[10] R. F. Steigerwald, "The corrosion behavior of some Fe-Cr alloys," Metallurgical Transactions, vol. 5, no. 11, pp. 2265-2269, 1974.

[11] C. Pallotta, N. De Cristofano, R. C. Salvarezza, and A. J. Arvia, "The influence of temperature and the role of chromium in the passive layer in relation to pitting corrosion of 316 stainless steel in $\mathrm{NaCl}$ solution," Electrochimica Acta, vol. 31, no. 10, pp. 12651270, 1986

[12] Z. Bou-Saleh, A. Shahryari, and S. Omanovic, "Enhancement of corrosion resistance of a biomedical grade 316LVM stainless steel by potentiodynamic cyclic polarization," Thin Solid Films, vol. 515, no. 11, pp. 4727-4737, 2007.

[13] N. Ramasubramanian, N. Preocanin, and R. D. Davidson, "Analysis of passive films on stainless steel by cyclic voltarnmetry and auger spectroscopy," Journal of The Electrochemical Society, vol. 132, no. 4, pp. 793-798, 1985.

[14] P. Schmuki, "From bacon to barriers: a review on the passivity of metals and alloys," Journal of Solid State Electrochemistry, vol. 6, no. 3, pp. 145-164, 2002.

[15] M. Da Cunha Belo, N. E. Hakiki, and M. G. S. Ferreira, "Semiconducting properties of passive films formed on nickelbase alloys type alloy 600: influence of the alloying elements," Electrochimica Acta, vol. 44, no. 14, pp. 2473-2481, 1999.

[16] N. B. Hakiki, S. Boudin, B. Rondot, and M. Da Cunha Belo, "The electronic structure of passive films formed on stainless steels," Corrosion Science, vol. 37, no. 11, pp. 1809-1822, 1995.

[17] K. Sieradzki and R. C. Newman, "A percolation model for passivation in stainless steels," Journal of The Electrochemical Society, vol. 133, no. 9, pp. 1979-1980, 1986.

[18] D. E. Williams, R. C. Newman, Q. Song, and R. G. Kelly, "Passivity breakdown and pitting corrosion of binary alloys," Nature, vol. 350, no. 6315, pp. 216-219, 1991.

[19] H. Böhni, "Breakdown of passivity and localized corrosion processes," Langmuir, vol. 3, no. 6, pp. 924-930, 1987.

[20] T. P. Hoar, D. C. Mears, and G. P. Rothwell, "The relationships between anodic passivity, brightening and pitting," Corrosion Science, vol. 5, no. 4, pp. 279-289, 1965.

[21] U. R. Evans, "The passivity of metals. Part I. The isolation of the protective film," Journal of the Chemical Society (Resumed), pp. 1020-1040, 1927. 
[22] K. J. Vetter and H.-H. Stehblow, "Entstehung und gestalt von korrosionslöchern bei lochfraß an eisen und theoretische folgerungen zur lochkorrosion," Ber. Bunsen-Gesellschaft Phys. Chem, pp. 1024-1035, 1970.

[23] N. Sato, "A theory for breakdown of anodic oxide films on metals," Electrochimica Acta, vol. 16, no. 10, pp. 1683-1692, 1971.

[24] T. P. Hoar, "The production and breakdown of the passivity of metals," Corrosion Science, vol. 7, no. 6, pp. 341-355, 1967.

[25] J. Soltis, "Passivity breakdown, pit initiation and propagation of pits in metallic materials-review," Corrosion Science, vol. 90, pp. 5-22, 2015.

[26] J. M. Kolotyrkin, "Pitting corrosion of metals," Corrosion, vol. 19, no. 8, pp. 261-268, 1963.

[27] T. P. Hoar and W. R. Jacob, "Breakdown of passivity of stainless steel by halide ions," Nature, vol. 216, no. 5122, pp. 1299-1301, 1967.

[28] T. Shibata and T. Takeyama, "Stochastic theory of pitting corrosion," Corrosion, vol. 33, no. 7, pp. 243-251, 1977.

[29] D. E. Williams, J. Stewart, and P. H. Balkwill, "The nucleation, growth and stability of micropits in stainless steel," Corrosion Science, vol. 36, no. 7, pp. 1213-1235, 1994.

[30] S. R. Taylor, "The investigation of corrosion phenomena with high throughput methods: a review," Corrosion Reviews, vol. 29, no. 3-4, pp. 135-151, 2011.

[31] K. Osozawa, K. Bohnenkamp, and H.-J. Engell, "Potentiostatic study on the intergranular corrosion of an austenitic chromium-nickel stainless steel," Corrosion Science, vol. 6, no. 9-10, pp. 421-433, 1966.

[32] Y. Yi, P. Cho, A. Al Zaabi, Y. Addad, and C. Jang, "Potentiodynamic polarization behaviour of AISI type 316 stainless steel in $\mathrm{NaCl}$ solution," Corrosion Science, vol. 74, pp. 92-97, 2013.

[33] X. Shang, Y. Zhang, N. Qu, and X. Tang, "Electrochemical analysis of passivation film formation on steel rebar in concrete," International Journal of Electrochemical Science, vol. 11, no. 7, pp. 5870-5876, 2016.

[34] Deutsche Edelstahlwerke, https://www.dew-stahl.com/service/ technische-bibliothekbroschueren/werkstoffdatenblaetter/.

[35] J. Morales, P. Esparza, R. Salvarezza, and S. Gonzalez, "The pitting and crevice corrosion of 304 stainless steel in phosphateborate buffer containing sodium chloride," Corrosion Science, vol. 33, no. 10, pp. 1645-1651, 1992.

[36] S. Omanovic and S. G. Roscoe, "Effect of linoleate on electrochemical behavior of stainless steel in phosphate buffer," Corrosion, vol. 56, no. 7, pp. 684-693, 2000.

[37] C. A. Acosta, R. C. Salvarezza, H. A. Videla, and A. J. Arvia, "The pitting of mild steel in phosphate-borate solutions in the presence of sodium sulphate," Corrosion Science, vol. 25, no. 5, pp. 291-303, 1985.

[38] S. A. M. Refaey, S. S. Abd El-Rehim, F. Taha, M. B. Saleh, and R. A. Ahmed, "Inhibition of chloride localized corrosion of mild steel by PO43-, CrO42-, MoO42-, and NO2- anions," Applied Surface Science, vol. 158, no. 3, pp. 190-196, 2000. 

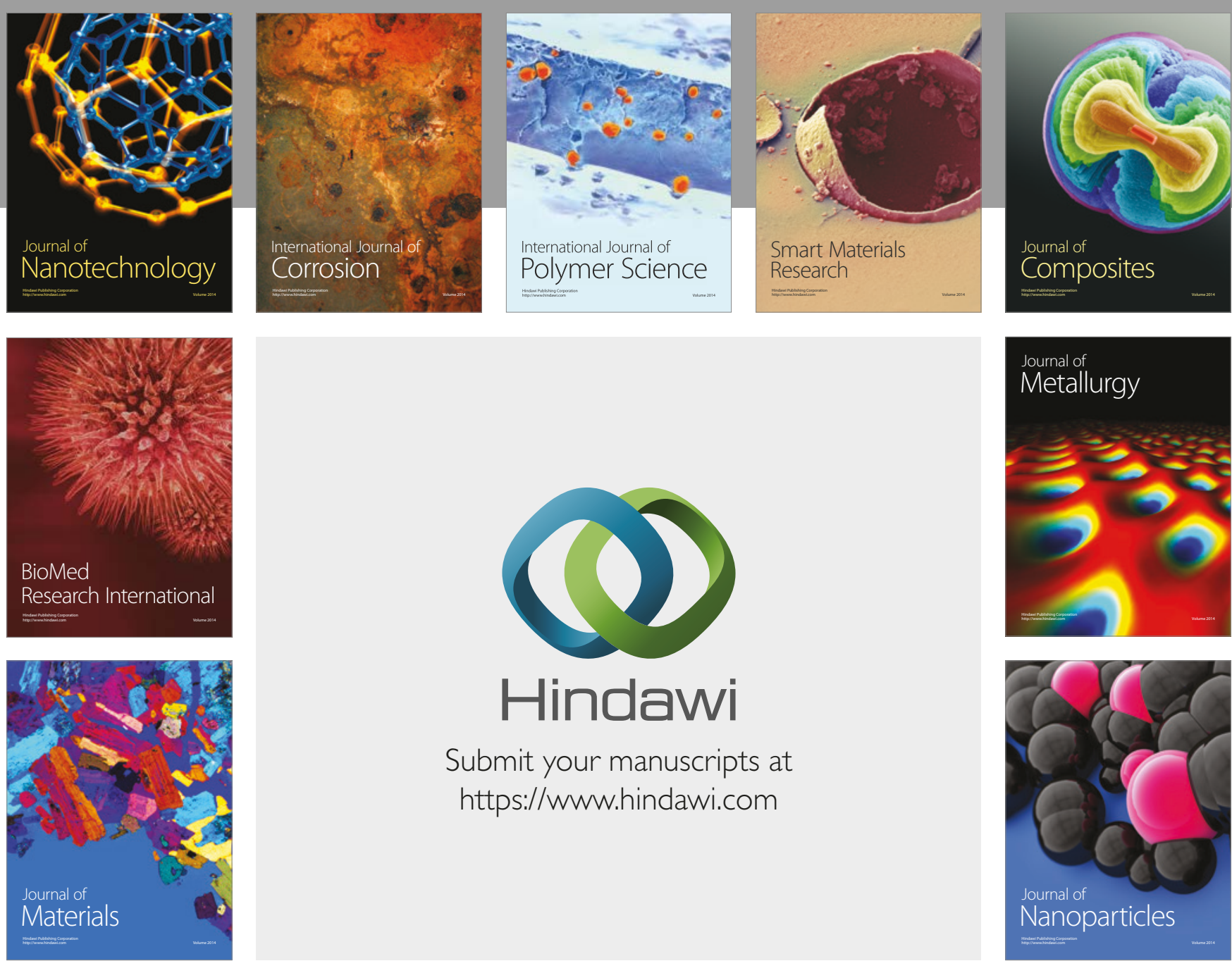

\section{Hindawi}

Submit your manuscripts at

https://www.hindawi.com
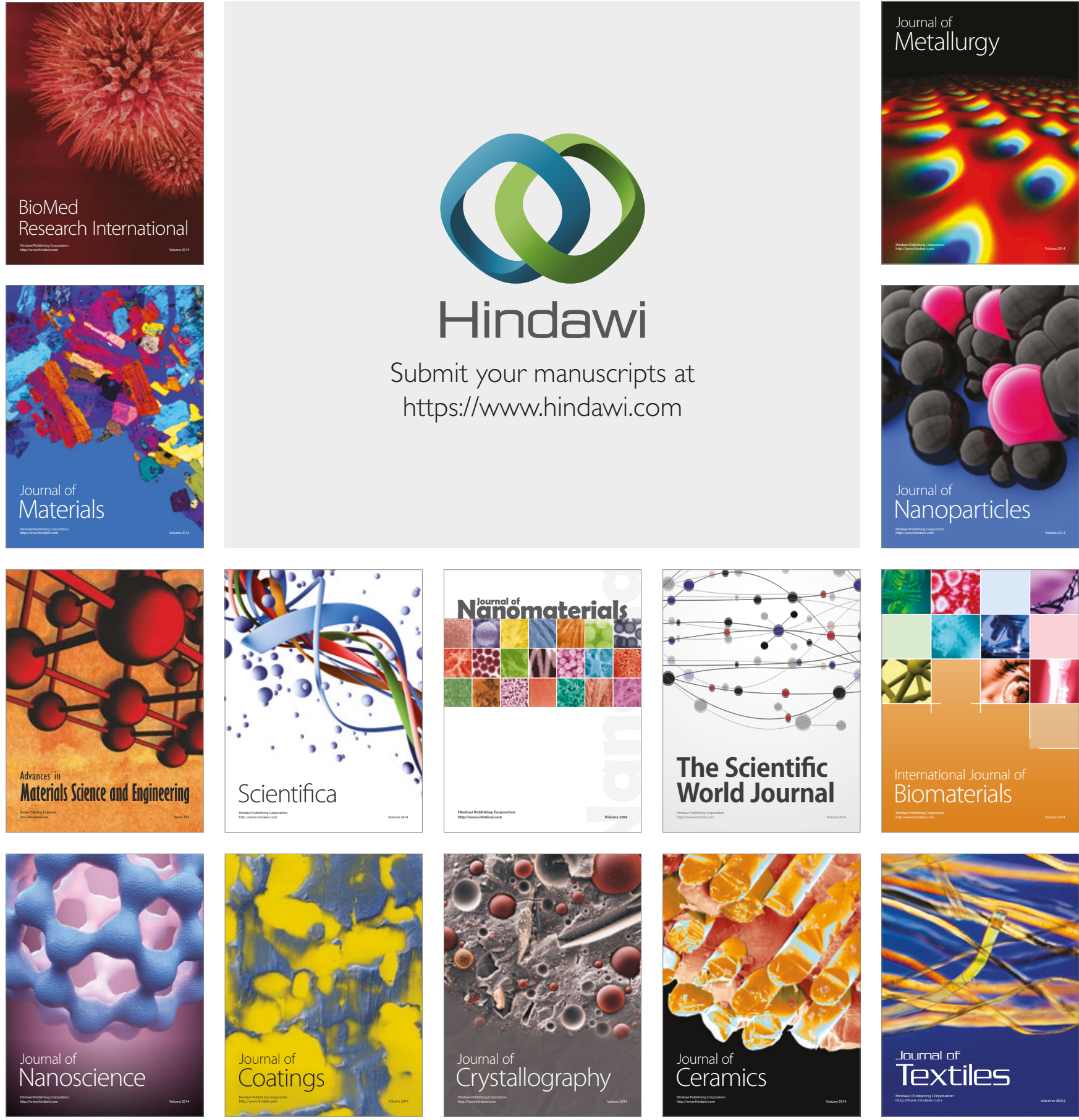

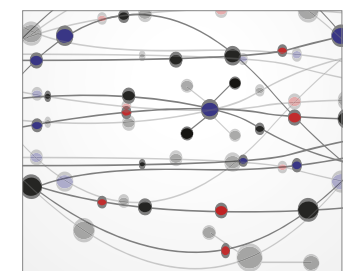

The Scientific World Journal
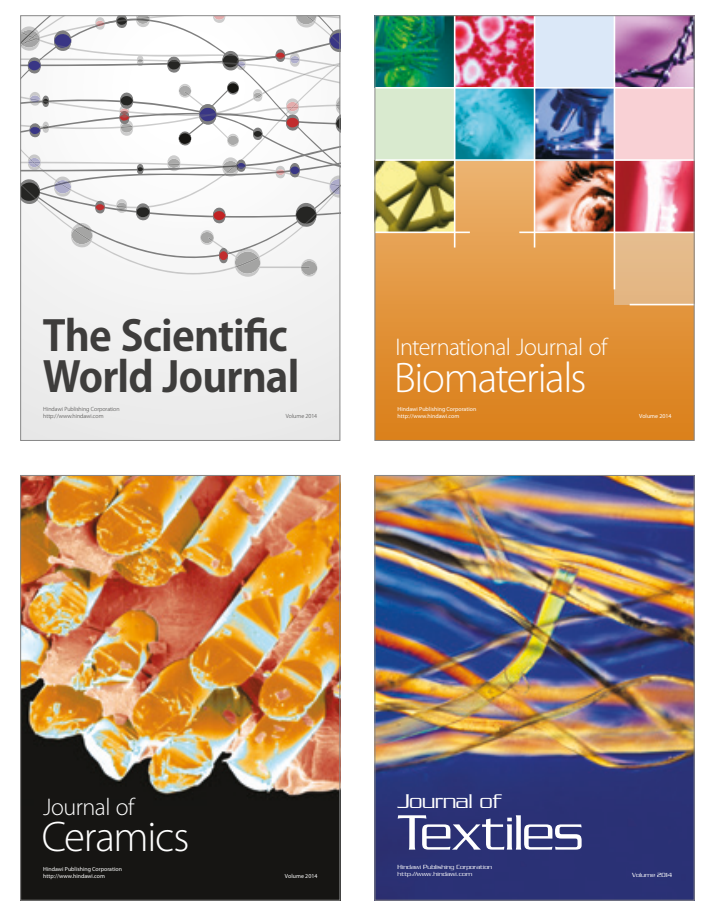